\title{
Lack of Association Between Meteorological Factors and Internal Medicine Admissions in New Orleans: Residents Perceptions Differ
}

\author{
Neal Dixit, B.S., Kristen Whalen, B.A., and Chayan Chakraborti, M.D. \\ Department of Medicine, Tulane University School of Medicine, New Orleans, LA, USA.
}

J Gen Intern Med 34(10):1975-6

DOI: $10.1007 / \mathrm{s} 11606-019-05091-7$

(c) Society of General Internal Medicine 2019

\section{INTRODUCTION}

In some regions, weather conditions have an impact upon emergency department (ED) visits, hospital admissions, and even mortality. ${ }^{1-3}$ Studies in other regions have shown no such impact of weather. ${ }^{4,5}$ Physician perceptions of this inconsistent phenomenon are unclear, particularly in internal medicine. We aimed to study the effect of weather on admissions at our hospitals and to determine if resident physicians working in these hospitals accurately perceived its impact.

\section{METHODS}

We analyzed the relationship between local weather and internal medicine (IM) admissions at two nearby centers in New Orleans over a 3-year period, 2013-2016. A two-sample $t$ test with equal variances was used to compare the binary variables (e.g., thunderstorm, heavy fog) provided by the National Climactic Data Center. Additional binary categories were created by categorizing continuous variables such as precipitation, average wind speed, and temperature into dichotomous variables. The cut-offs are representative of unusual weather for New Orleans. Continuous variables were also analyzed using Spearman correlation. The day of admission was defined by the time the admission order was recorded by the hospital EMR. A two-tailed $p$ value of $<0.05$ was considered significant. All statistical analyses were performed using Stata 9.2 (StataCorp, College Station, TX). Additionally, we surveyed 122 Tulane IM residents' perceptions of the effect of weather on medical admissions. This study was determined to be exempt by the Institutional Review Board.

\section{Prior Presentations None.}

Published online June 12, 2019

\section{RESULTS}

Table 1 shows the average number of admissions by meteorological factor. Weather variables did not demonstrate a significant relationship with hospital admissions. Spearman correlation of precipitation, high temperature, low temperature, and average wind speed showed no effect on medical admissions rate.

The IM resident response rate to the survey was $43 \%$. Table 2 shows the results of the first set of questions. Additionally, $79 \%$ of residents anticipated a $25 \%$ or greater decrease in admissions on a day of $>1$ in. precipitation. Thirty-one percent of residents anticipated a $25 \%$ or greater increase in admissions on a day with poor air quality.

\section{DISCUSSION}

Our study of two hospitals in New Orleans showed no meteorological factor had a significant association with medical admission rate. From our analysis, we can reasonably say that patients do not appear to have difficulty getting to these hospitals in adverse conditions nor do these conditions predispose our patients to present with medical conditions requiring admission on the same day.

Our results may differ from previous studies for several reasons. First, the subtropical climate of New Orleans, combined with rainfall that is evenly distributed across the year, does not pose a significant barrier for patients to

Table 1 Mean Number of Admissions by Meteorological Factor

\begin{tabular}{lllll}
\hline \hline & $\boldsymbol{n}$ & Avg. admits & SD & P value \\
\hline High temp $\geq 95^{\circ} \mathrm{F}$ & 27 & 20.93 & 7.24 & 0.74 \\
High temp $<95^{\circ} \mathrm{F}$ & 776 & 20.55 & 5.99 & - \\
Low temp $\leq 35^{\circ} \mathrm{F}$ & 25 & 19.36 & 6.15 & 0.31 \\
Low temp $>35^{\circ} \mathrm{F}$ & 778 & 20.60 & 6.03 & - \\
Precip. $>1$ in. & 40 & 19.20 & 5.67 & 0.14 \\
Precip. $<1$ in. & 763 & 20.63 & 6.05 & - \\
Avg. wind $>15 \mathrm{MPH}$ & 30 & 19.50 & 7.20 & 0.33 \\
Avg. wind $<15 \mathrm{MPH}$ & 773 & 20.60 & 5.98 & - \\
Thunderstorm & 108 & 21.46 & 6.09 & 0.09 \\
No thunderstorm & 695 & 20.42 & 6.01 & - \\
Smoke or haze & 101 & 21.46 & 6.17 & 0.11 \\
No smoke or haze & 702 & 20.43 & 6.01 & - \\
Heavy fog & 26 & 21.46 & 5.93 & 0.44 \\
No heavy fog & 777 & 20.53 & 6.04 & - \\
Total & 803 & 20.56 & 6.03 & - \\
\hline
\end{tabular}


Table 2 Percentage of Respondents Strongly Agreeing or Agreeing That Each Meteorological Factor Affected the Number of Admissions

\begin{tabular}{llll}
\hline \hline & $\begin{array}{l}\text { \% of respondents agreeing } \\
\text { or strongly agreeing }(\boldsymbol{n}=\mathbf{5 3})\end{array}$ & $\begin{array}{l}\text { \% of respondents agreeing or } \\
\text { strongly agreeing, age }<\mathbf{3 0} \text { years } \\
(\boldsymbol{n}=\mathbf{3 1})\end{array}$ & $\begin{array}{l}\text { \% of respondents agreeing or } \\
\text { strongly agreeing, age 30-50 years } \\
(\boldsymbol{n}=\mathbf{2 2})\end{array}$ \\
\hline Weather (in general) & $88 \%$ & $97 \%$ & $\begin{array}{l}\boldsymbol{P} \\
\text { value }\end{array}$ \\
Rain & $82 \%$ & $84 \%$ & $79 \%$ \\
Temperature extremes & $72 \%$ & $88 \%$ & $79 \%$ \\
Sustained high winds & $28 \%$ & $34 \%$ & 0.043 \\
Reduction in air quality & $32 \%$ & $29 \%$ & 0.74 \\
(e.g., pollen or smog) & & & 0.005 \\
\hline
\end{tabular}

get to the hospital. ${ }^{6}$ Additionally, patient health may be unaffected by climate that lacks extreme heat or cold. In contrast, more unusual or extreme conditions may be the reason for a significant effect of weather found in certain areas; e.g., infrequent heavy rain in a dry climate or extreme cold and snowfall in the northern US.

Second, patients with major medical issues that ultimately require admission may not be deterred from visiting the hospital during poor weather. In contrast, milder medical concerns which do not result in admission from the ED may be more easily influenced by inclement weather. This would explain why numerous studies have shown a relationship between weather and ED visits, whereas admissions were not correlated in the present study.

Despite the lack of association between weather and IM admissions at our hospital, IM residents believed that such an association exists and that rain and cold temperature were the strongest factors affecting admissions. The belief was more pronounced in residents under the age of 30 years, suggesting that with more experience, clinicians realize that weather may be a less prominent factor. The exact reason for this wide spread belief is unclear. It may be related to residents training in areas where weather does affect admissions, resident knowledge of previous studies, or superstition. Limitations of this study include only studying the effect of weather on the day of admission at only two hospitals in a subtropical city. Additionally, the survey did not include patient perspectives.

We conclude that resident perception of the effect of weather on medical admissions did not match reality at our hospitals.
Decisions based on daily weather should incorporate institutional and local weather data.

Corresponding Author: Chayan Chakraborti, M.D.; Department of Medicine, Tulane University School of Medicine, New Orleans, LA, USA (e-mail: cchakrab@tulane.edu).

\section{Compliance with Ethical Standards:}

Conflict of Interest: The authors declare that they do not have a conflict of interest.

\section{REFERENCES}

1. Ou DKB, To TP, Taylor DM. Weather patients will come? Med J Aust 2005; 183(11 12):675-677.

2. Schwartz J, Samet JM, Patz JA. Hospital admissions for heart disease The effects of temperature and humidity. Epidemiology. 2004;15(6):755761 .

3. Kovats RS, Hajat S, Wilkinson P. Contrasting patterns of mortality and hospital admissions during hot weather and heat waves in Greater London, UK, Occup Environ Med 2004;61(11):893-898.

4. Attia MW, Edward R. Effect of weather on the number and the nature of visits to a pediatric ED. Am J Emerg Med 1998;16(4):374-375.

5. Zibners LM, Bonsu BK, Hayes JR, Cohen DM. Local weather effects on emergency department visits - A time series and regression analysis. Pediatr Emerg Care 2006;22(2): 104-106.

6. Climate New Orleans - Louisiana. 2018; https://www.usclimatedata.com/ climate/new-orleans/louisiana/united-states/usla0338. Accessed 4/11/18.

Publisher's Note Springer Nature remains neutral with regard to jurisdictional claims in published maps and institutional affiliations. 